\title{
Libraries and international infrastructure for Open Access services
}

\author{
Elmar Mittler \\ Director, State and University Library Göttingen, Germany
}

For the purpose of this presentation, I am not speaking on behalf of the Frankfurt Group. The Frankfurt Group represents a group of publishers and authors dedicated to the facilitation of discussion and the promotion of positive relations between the various players in the publishing world. Frequently, we use the same words but attach different meanings. Since we share many common interests, this sort of misunderstanding is unnecessary. Our mission is to use these common interests to find practical progress.

My presentation will focus on the historical view of library history. Firstly, I would like to mention Alexandria, where, due to the life span of papyrus paper, librarians had to transcribe all manuscripts and data every 150 years. Therefore, it was necessary to destroy the library on a regular basis. At the end of the 14th century, Professor Van Ingin transported his book collection from Paris to Heidelberg, where he founded the university library. At that time, thanks to professors and student book contributions, all universities became self-sufficient information providers. Of course, in the 16th century, this situation changed after the invention after invention of printing press, which allowed publishers to increase book distribution.

The Göttingen University, which was founded by the King of England, established the first research university. The aim of this library was to look for all books showing the progress of knowledge. In many respects, this represented the birth of modern libraries. The concept of a research library, taking the best research material from all over the world and paying for it, means that libraries have been the financial lifeblood of research. In addition, they provide free access and archiving services for this and future generations of researchers.

The library of the future has a chance to realise the dreams of librarians and end users. It can provide local holdings and interlibrary loans in printed or electronic form, at any time within a secure network for legitimate users. Although cross-linking has become associated with publishing activities, we should not forget that cross-linking started in libraries.

Thanks to digitisation, the entire range of cultural and historical material will become more widely available. For example, the digitisation of the Gutenberg Bible makes him the man of this millennium just as he was the man of the last millennium.

Concerning the publishing marketplace, which was mentioned today, libraries are encountering some problems. Due to the amount of money required to subscribe to the journals of the larger players, they are unable to cater for the smaller scale publications.

To help both libraries and small publishers, we try to encourage the use of consortia to provide improved access. Although we accept that no one is entitled to a free lunch, a four star dinner should still be available at a reasonable price. 
In my view, we should distinguish between communication and publication, which includes a peer review process. In University IT departments, information is organised on three levels: a layer for private material; a layer for Intranet material and a layer for peer reviewed material that is freely available on the Internet. With the exception of peer review, all these activities correspond to normal university activities. Since researchers require the facilities to compile long-term archiving, internationally accepted laws should be in place to allow them to act accordingly.

As we heard earlier, archiving is relevant on two levels: long time preservation and permanent access. It is pointless to keep hidden archives. To ensure a speedy and acceptable outcome, we need real organisation on an international level.

The future system of publication and communication should include pre-prints, peer review articles and journals. In this system, publishers should provide added value publications, aggregating peer reviewed articles in co-operation with universities and the specialised organisations. In this respect, the LIBER association has done a lot by organising conferences and promoting new quality schemes, such as personal and usage-oriented impact factors instead of journal and citation impact factors.

In conclusion, we have a real opportunity to use libraries as a worldwide infrastructure providing standardised published and online information, offering short- and long-term access to all kinds of material. However, this service should be provided in co-operation with researchers, universities, learned societies and publishers.

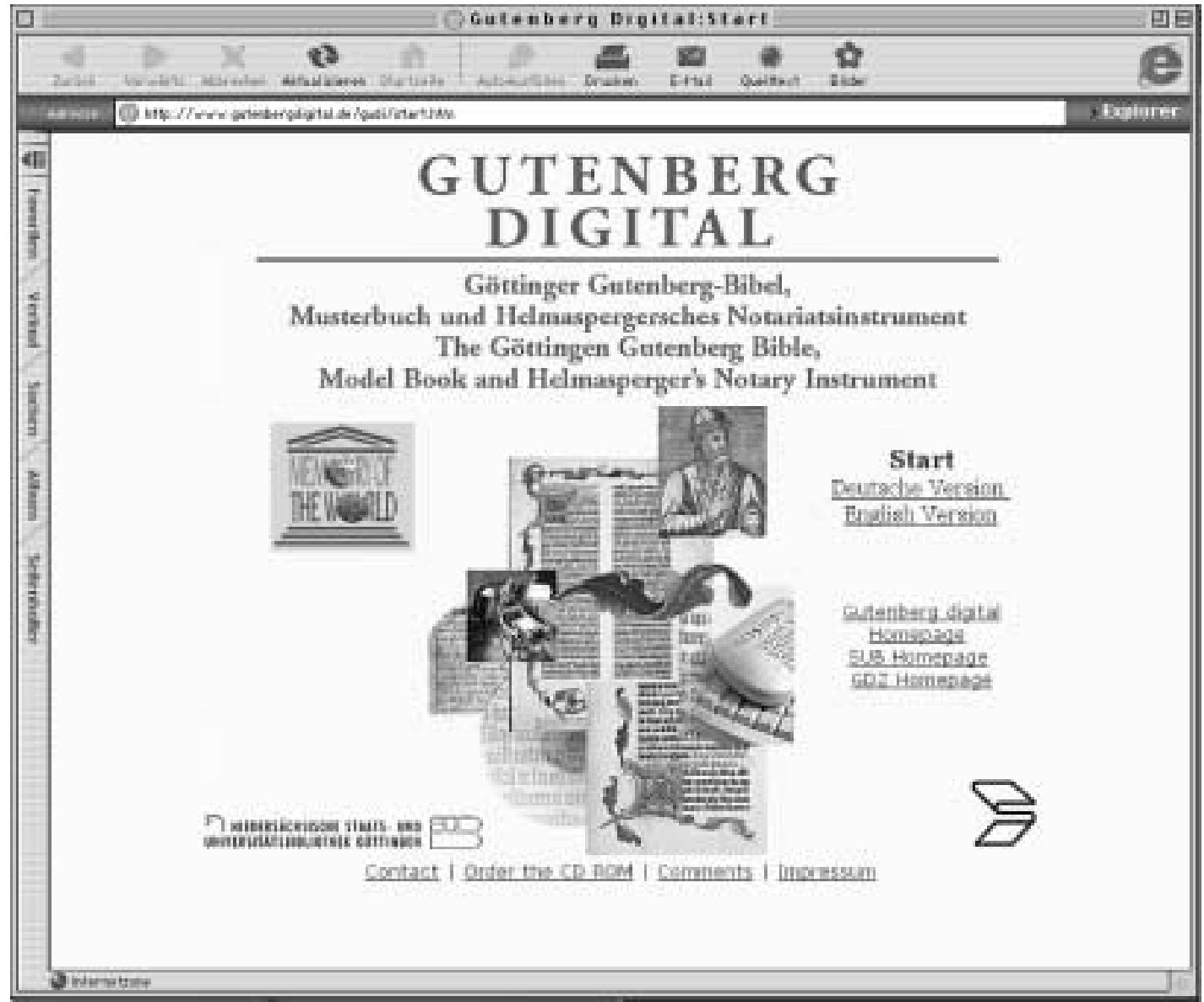

